\title{
Pratiques Economiques et transactions avec les Ancêtres. Étude des cérémonies famadihana dans un village malgache
}

Thèse de Doctorat (PhD), Louvain-la-Neuve (Belgique), Université catholique de Louvain (UCL), 2012

\section{Antoine Deliége}

\section{OpenEdition} Journals

Édition électronique

URL : http://journals.openedition.org/anthropodev/324

DOI : 10.4000/anthropodev.324

ISSN : 2553-1719

Éditeur

APAD - Association pour l'anthropologie du changement social et du développement

\section{Édition imprimée}

Date de publication : 1 septembre 2014

Pagination : 187-188

ISBN : 9791093476018

ISSN : 2276-2019

Référence électronique

Antoine Deliége, «Pratiques Economiques et transactions avec les Ancêtres. Étude des cérémonies famadihana dans un village malgache », Anthropologie \& développement [En ligne], 40-41 | 2014, mis en ligne le 01 septembre 2016, consulté le 24 septembre 2020. URL : http://journals.openedition.org/ anthropodev/324; DOI : https://doi.org/10.4000/anthropodev.324

\section{(c) (†)}

La revue Anthropologie \& développement est mise à disposition selon les termes de la Licence Creative Commons Attribution 4.0 International. 


\title{
Pratiques Economiques et transactions avec les Ancêtres
}

\section{Étude des cérémonies famadihana dans un village malgache}

\author{
Antoine Deliége ${ }^{1}$ \\ Thèse de Doctorat (PhD), Louvain-la-Neuve (Belgique), \\ Université catholique de Louvain (UCL), 2012
}

\section{Résumé}

La thèse part d'un constat: le mépris des élites urbaines malgaches envers les communautés rurales, et plus particulièrement envers leurs coutumes ancestrales qui freineraient le développement économique de Madagascar et maintiendraient les indicateurs de pauvreté de la Grande lle dans le rouge. Pourtant, cette population rurale considérée comme très pauvre parvient à organiser chaque année des festivités très coûteuses pour honorer ses ancêtres, telles que le Famadihana ou cérémonies du retournement des morts. Dès lors, comment peut-elle accumuler tant de richesses en si peu de temps alors que d'habitude elle arrive à peine à nourrir ses membres? Ensuite, nous nous sommes demandé pourquoi des populations vivant sous le seuil de pauvreté " gaspilleraient-elles » le peu qu'elles arrivent à accumuler pour des morts qui, par définition, ne reviendront pas. Autrement dit, pourquoi n'investissent-elles pas dans des domaines plus productifs comme l'achat de matériel agricole, d'engrais chimiques, afin d'augmenter les surplus agricoles et ainsi accroître d'autant leurs revenus monétaires et leurs conditions matérielles d'existence quotidienne ? Nous pourrions dire qu'elles ne parviennent pas à - ou ne veulent pas - rattraper leur "retard " en terme de développement, que leur mode de vie est incompatible avec celui du monde capitaliste moderne mais, au fond, nous n'aurions rien expliqué. Nous nous sommes alors intéressé à l'étude de cette cérémonie non pas du point de vue uniquement cérémoniel, mais d'une manière holistique autour du concept de productivité, c'est-à-dire en prenant en compte non seulement l'étude de la sphère économique et sociale mais également de la sphère symbolique.

La thèse s'est ainsi penchée sur la question de l'universalité du concept de productivité qui transcenderait les différences culturelles et historiques entre les peuples. Dans un premier temps, une revue critique de la littérature socioanthropologique et économique a permis d'établir une synthèse pour l'analyse d'un phénomène empirique comme le Famadihana. Le matériel empirique repose

${ }^{1}$ E-mail : antoinedeliege@yahoo.fr

Ces travaux ont été édités aux Presses universitaires de Louvain, voir http://pul.uclouvain.be. 
sur l'étude d'une communauté paysanne dans le village d'Amboasary, situé à une trentaine de kilomètres au sud de la capitale malgache, dans lequel nous avons récolté les données de septembre 2005 à juin 2007.

L'approche adoptée s'est voulue transversale en prenant en compte la totalité de l'édifice social pour aller rechercher, tant au niveau micro avec les motivations que macro avec des institutions et des rapports sociaux, qui en apparence n'ont parfois rien de strictement "économique ", des formes de production et de répartition des biens assurant la base matérielle nécessaire à toute vie en société. L'introduction d'autres sphères que celle de l'économie (politique, sociale et culturelle) nous a permis de nous ouvrir aux logiques économiques indigènes. En organisant des cérémonies en l'honneur des ancêtres, les pratiques économiques (définies sommairement par la production, dans ses différentes formes, la répartition ou la distribution, puis la consommation) ont pour finalité de s'engager dans des transactions avec les morts. Ces transactions, ne pouvant s'effectuer à travers de l'argent, doivent être dominées par un jeu perpétuel du donnant-donnant, et toute cérémonie s'accompagne du don d'objets (nourriture et autres) de la part des descendants suivi d'un contre-don (bénédictions) de la part des ancêtres. Le matériel empirique nous a montré que cet échange réciproque prendra un caractère non seulement cérémoniel mais également ostentatoire : chaque homme plaçant son honneur et son prestige dans sa capacité à produire et dans sa générosité à distribuer.

Il est donc encore difficile voire impossible de saisir les logiques de développement communautaire en dehors de leur substrat social et culturel. Autrement dit, la modernité en relation avec l'insertion du médium argent ne signifie pas, ici, diminution des rituels traditionnels. Au contraire, l'économie reste soumise aux impératifs ancestraux c'est-à-dire au social et au symbolique. Ici, la richesse, avant d'être économique, est tout d'abord sociale et symbolique puisqu'elle est la condition intrinsèque de la reconnaissance et de la production/reproduction de liens sociaux. Ceux qui ont réussi socialement et économiquement ont, pour cette raison, comme projets la perpétuation de leur prestige après leur passage dans ce monde. 